\title{
Points of View of Chilean Adolescents about Asking for Help and Suggestions to Prevent Dating Violence Based on an Ecological Systems Theory
}

\author{
Tatiana Sanhueza1, Geneviève Lessard ${ }^{2}$, Maruzzella Valdivia-Peralta ${ }^{3}$, Cecilia Bustos-Ibarra1 \\ ${ }^{1}$ Department of Social Work, Faculty of Social Sciences, University of Concepción, Concepción, Chile \\ ${ }^{2}$ School of Social Work and Criminology, Laval University, Québec, Canada \\ ${ }^{3}$ Department of Psychology, Faculty of Social Sciences, University of Concepción, Concepción, Chile \\ Email: tsanhueza@udec.cl
}

How to cite this paper: Sanhueza, T., Lessard, G., Valdivia-Peralta, M., \& Bustos-Ibarra, C. (2022). Points of View of Chilean Adolescents about Asking for Help and Suggestions to Prevent Dating Violence Based on an Ecological Systems Theory. Open Journal of Social Sciences, 10, 458-477.

https://doi.org/10.4236/jss.2022.101034

Received: December 24, 2021

Accepted: January 25, 2022

Published: January 28, 2022

Copyright $\odot 2022$ by author(s) and Scientific Research Publishing Inc. This work is licensed under the Creative Commons Attribution-NonCommercial International License (CC BY-NC 4.0). http://creativecommons.org/licenses/by-nc/4.0/

\begin{abstract}
While several programs have been developed to prevent dating violence, few have been evaluated. Likewise, few studies have documented adolescents' viewpoints on how prevention should be done. The current qualitative study seeks to strategically fill a gap in knowledge regarding the points of view of Chilean adolescents about the strategies that are best suited to prevent this problem and what is relevant content for prevention programs. This paper is part of a broader study on adolescents' social representations of dating violence. The study's aim was to explore Chilean adolescents' points of view about asking for help and their suggestions about how to prevent dating violence. The sample included 48 Chilean adolescents, 26 girls (54.1\%) and 22 boys ( $45.8 \%$ ) between 14 and 18 years old, recruited from public and private schools, who were interviewed with a focus group method. The study consisted of two phases; the results of the second phase are discussed in this manuscript. The results are useful for the development of an appropriate socio-political response to this social and public health problem. Participants identified friends and parents as more common sources from whom to seek help than teachers and health professionals. The severity of dating violence and ensuing injuries are the main reasons for asking for help. In addition, gender is considered a central prevention issue in a changing Chilean cultural context. According to the ecological systems theory, prevention strategies based on the environment of adolescents at multiple levels (individual, interpersonal, community, and social) and in multiple components have been recommended.
\end{abstract}




\section{Keywords}

Adolescents, Dating Violence, Prevention, Ecological Systems Theory, Chile

\section{Introduction}

Dating violence (DV) is a serious social and public health problem in several countries. Considering its high prevalence (Valdivia-Peralta, Fonseca-Pedrero, González-Bravo, \& Paino, 2019), the risks of revictimization in adulthood (Cui, Ueno, Gordon, \& Fincham, 2013), and the consequences for affected adolescents (Fernández-Fuertes \& Fuertes, 2010), it is essential to make a concerted effort to prevent it. Researchers' attention has been captured more by individual risk and protective factors, while social and environmental factors have gone largely ignored (Johnson, Parker, Rinehart, Nail, \& Rothman, 2015; D’Iverno, Kearns, \& Reidy, 2018).

In the case of the South American country of Chile, it has no public policy aimed at preventing DV or helping the adolescents concerned (SERNAM, 2012; Ministerio de Salud [MINSAL], 2013, Valdivia-Peralta et al., 2019). This invisibility of adolescents in the intimate or family violence field is also observed at the legislative level. Just on November 23, 2021, Law No. 21,393, which appoints February 7 as the "National day of non-violence in dating" (Ministerio de Justicia, 2021), was published officially, but there is still no law that sanctions this problem. The current law 20,066 (Ministerio de Justicia, 2005), sanctions intra-family violence that occurs exclusively between people united by marital, consanguineous, or parental ties (such as ex-partners who have a child in common), affinity, or conjugal coexistence.

Although several studies have addressed the challenges of designing prevention programs tailored to the characteristics of adolescents, few have qualitatively explored their viewpoints (Fellmeth, Heffernan, Nurse, Habibula, \& Sethi, 2013). Highlighting the way in which adolescents conceive of prevention strategies represents an opportunity to give them a voice and to reinforce the idea that they are the actors best placed to find solutions for the problems that affect them (Adams \& Williams, 2011b).

This article presents the results of a qualitative study on the social representations of DV in Chilean adolescents. The study objective was to explore Chilean adolescents' points of view about asking for help and their suggestions about how to prevent DV. Using ecological systems theory, the results concerning requests for help and the prevention suggestions provided by the participants will be presented.

\section{State of Knowledge about the Request for Help and Prevention of Dating Violence}

\subsection{Requests for Help: Sources and Barriers}

Several studies show that when adolescents experience DV, they seek help from 
more informal sources, namely friends, parents, and family (Adams \& Williams, 2011a; Mayoyo, Ogeno, \& Likoye 2020; Weisz \& Black, 2009). Conversely, teachers are most often mentioned with regard to requests for help from formal sources. Health professionals and religious authorities are not however believed by adolescents to be sources of help (Ocampo et al., 2007). Other studies indicate, furthermore, that adolescents recognize that they are a source of help for their peers who are experiencing DV; they likewise recognize that they are able to offer emotional support and counseling to their friends in difficulty (Gallopin \& Leigh, 2009; Van Camp, Hébert, Guidi, Lavoie, \& Blais, 2014).

Diverse obstacles to seeking help include the emotions experienced by DV victims such as shame (Ocampo et al., 2007), fear of retaliation by the romantic partner (Burton, Halpern-Felsher, Rehm, Rankin, \& Humphreys, 2013), and the idea that asking for help is a sign of vulnerability (Rueda, Williams, \& Nagoshi, 2015). Gender specificities are mentioned. For example, girls generally ask for more help than boys (Fry, Messinger, Rickert, O'Connor, Palmetto, Lessel, \& Davidson, 2013). Boys, on the other hand, have more difficulty recognizing the DV they have suffered and a perceived inability to deal with this type of situation (Van Camp et al., 2014). They likewise fear being laughed at if they admit to being victims of DV (Black, Tolman, Callahan, Saunders, \& Weisz, 2008). Social norms, moreover, reinforce these gender distinctions (Gallopin \& Leigh, 2009; Sabina, Cuevas, \& Rodriguez, 2014).

Other barriers that inhibit adolescents from seeking help include: the adolescents' lack of knowledge of the existing services (Mayoyo, Ogeno, \& Likoye 2020; Sabina et al., 2014), an inadequate intervention for adolescents, and the lack of screening protocols (e.g., in schools) (Moore, Sargenton, Ferranti, \& Gonzalez-Guarda, 2015). The attitudes of teachers or school personnel, who do not consider DV to be a serious problem in adolescence and who believe that preventing it is not their responsibility, is another possible obstacle (Khubchandani, Price, Thompson, Dake, Wiblishauser, \& Telijohann, 2012; Sundaram, 2016). In addition, their friends' lack of romantic experience (Van Camp et al., 2014) and the adolescents' ongoing process of autonomy and distancing from their parents (Ocampo et al., 2007) can also be barriers to asking for help.

\subsection{Prevention of DV}

Evaluations of prevention programs indicate that the most effective interventions include multiple levels of action (individual, family, school, and community) (Rothman, Bair-Merritt, \& Tharp, 2015; Rothman, Edwards, Rizzo, Kearns, \& Banyard, 2019). Prevention should be aimed at adolescents and people close to them (friends, parents, and teachers). Likewise, several studies raise the importance of intervening in the early stages and over the long-term, and focusing on children by providing content adapted to the age of the participants (Underwood \& Rosen, 2009), as well as on the central role of parents in prevention (Black \& Preble, 2016; Rothman, Miller, Terpeluk, Glauber, \& Randel, 2011). In 
addition, all types of violence should be considered: psychological, physical, and sexual (Fox, Hale, \& Gadd, 2014). Currently, most prevention programs focus on individual factors, such as modifying attitudes favorable to violence among adolescents (D'Iverno et al., 2018). However, DV prevention programs aimed at Latin American adolescents reveal the importance of the family in their culture and of taking this into account in the development of prevention strategies (Gonzalez-Guarda et al., 2014; Rueda et al., 2015).

\section{Theoretical Framework}

Dutton (1985) proposed a theory of violence based on the ecological systems theory of Bronfenbrenner (1979), who defines the ecological system as a set of concentric circles, each one fitting into the next and exerting a mutual influence between the environment and the individual. Applied to violence, this approach conceptualizes the problem as a multifaceted phenomenon grounded in an interplay between personal, situational, and sociocultural factors (Heise, 1998), and comprising four levels: 1) Individual level (ontosystem) refers to "the personal history factors that each individual brings to his or her behavior and relationships" (Heise, 1998: p. 264), which implies experiences and personality characteristics that influence the response to microsystem and exosystem stressors (Heise, 1998). Some factors related to DV are: witnessing intimate partner violence or being abused oneself as a child, adopting attitudes conducive to violence, using alcohol or drugs, lacking conflict resolution skills in the couple, etc. 2) Interpersonal level (microsystem) refers to the most immediate relational environment, constituted by the face-to-face interactions that the individual maintains in the closest environment, especially with the nuclear and extended family (Heise, 1998). Applied to DV, the relationships between parents and children, peer influences, and so forth are mentioned. 3) Community level (exosystem) is made up of formal and informal social structures and institutions, including the world of work, the neighborhood, and social networks, and institutions such as health, education, religion, and government (Heise, 1998). Some factors related to DV at this level are: low socioeconomic family status, delinquent peer associations, existence or not of laws, social policies or programs addressing the prevention of DV, access to weapons, school violence, and so on. 4) Society level (macrosystem), "refers to the broad set of cultural values and beliefs that permeate and inform the other three layers of the social ecology" (Heise, 1998: p. 277), for example: rigid gender roles, acceptance of interpersonal violence, a patriarchal system, and "machismo" in the Latino culture. Other examples include social inequalities, structural and institutional violence, and social representations of violence, romantic relationships, and adolescence.

The theory has been widely used to identify the risk and protection factors of violence (Foshee, Benefield, Ennett, Bauman, \& Suchindran, 2004; Fredland, Ricardo, Campbell, Sharps, Kub, \& Yonas, 2005; Gracia Leiva, Puente Martínez, Ubillos Landa, \& Páez Rovira, 2019; Pittenger, Huit, \& Hanse, 2016). However, 
there is still limited knowledge about the sources and barriers in the request for help by adolescents who experience DV and the interaction between factors from different levels of the ecological system theoretical framework in preventing DV efforts. If we consider that DV is a multifactorial problem, the ecological systems theory seems helpful to inquire about the solutions at different levels and design prevention programs considering them.

\section{Method}

\subsection{Sampling}

This study includes 48 adolescents from 9th and 10th grades. Due to the high degree of social segregation in Chilean schools (Torche, 2005), where the most socially privileged students go to private schools while the less privileged students go to public schools, it was decided to recruit participants from public $(\mathrm{n}=$ 4) and private schools $(\mathrm{n}=3)$ in the Province of Concepción in Chile. 26 girls (54.1\%) and 22 boys (45.8\%) between the ages of 14 and 18 participated, with an average age of $16,52 \%$ of the participants living in a nuclear family. Most of the respondents described themselves as being middle-class (87.4\%). At the time the research was conducted, most of the respondents $(85.3 \%)$ had already had a romantic relationship (Table 1).

\subsection{Procedure}

Following the approval of the corresponding institutional research ethics committee of the Laval University, adolescents were invited to participate in the research. The first author visited classes in seven schools that agreed to collaborate on recruitment (grades 9 and 10) to provide explanations on the research, its objectives, and the modalities of participation. They were invited to participate in the two data collection phases, one based on free association (first phase) and the other on focus groups (second phase). Questions about the research from potential participants were answered at that time. A consent form was given to the students so that they could discuss the research goals with their parents and return the signed forms within approximately two weeks prior to the collection data.

\subsection{Data Collection Method}

The focus group method was selected due to the importance that peers have in adolescence, this method making it easier to reproduce adolescents' daily conversations (Letendre \& Williams, 2014). The focus groups were held outside of class time. Groups $(\mathrm{n}=12)$ lasted from 90 to $120 \mathrm{~min}$ and were moderated by the main researcher and a male or female research assistant depending on each group's make-up (6 groups composed of girls and 6 groups of boys). The empirical saturation was achieved in the third group for each gender (Morgan, 1997).

An interview guide was used to encourage exchanges among the participants. 
Table 1. Participants' socio-demographic chracteristics.

\begin{tabular}{|c|c|c|c|}
\hline \multirow{2}{*}{ Variables } & \multicolumn{3}{|c|}{ Focus group $(n=48)$} \\
\hline & & Girls \% (n) & Boys \% (n) \\
\hline Sex & & $54.1(26)$ & $45.8(22)$ \\
\hline \multirow[b]{2}{*}{ Age } & & $X=15.7$ & $X=15.9$ \\
\hline & & SD 0.7 & SD 0.9 \\
\hline \multirow{3}{*}{ Family type } & Nuclear & $29.1(14)$ & $22.9(11)$ \\
\hline & Extended & $20.8(10)$ & $14.5(7)$ \\
\hline & Single-parent & $4.1(2)$ & $8.3(4)$ \\
\hline \multirow{2}{*}{ School type } & Public & $29.1(14)$ & $22.9(11)$ \\
\hline & Private & $25(12)$ & $22.9(11)$ \\
\hline \multirow{4}{*}{$\begin{array}{l}\text { Perception of } \\
\text { Income (a) }\end{array}$} & Low & $2.1(1)$ & $2.1(1)$ \\
\hline & Middle & $45.8(22)$ & $41.6(20)$ \\
\hline & High & $4.1(2)$ & $2.1(1)$ \\
\hline & Did not answer & $2.1(1)$ & -- \\
\hline \multirow{6}{*}{$\begin{array}{l}\text { Perception of } \\
\text { neighborhood }\end{array}$} & Very dangerous & $2.1(1)$ & -- \\
\hline & Dangerous & $6.2(3)$ & $2.1(1)$ \\
\hline & Neither dangerous nor safe, but quiet & $18.7(9)$ & $16.6(8)$ \\
\hline & Safe & $18.7(9)$ & $8.3(4)$ \\
\hline & Very safe & $8.3(4)$ & $2.1(1)$ \\
\hline & Did not answer & -- & \\
\hline \multirow{2}{*}{$\begin{array}{l}\text { Romantic } \\
\text { relationship }\end{array}$} & Yes & $43.7(21)$ & $41.6(20)$ \\
\hline & No & $10.4(5)$ & $4.1(2)$ \\
\hline
\end{tabular}

a. The perception of income given here is that which the participants used to define themselves.

The main questions related to this article were: 1) If you were experiencing an abusive situation with your partner, would you ask for help? If so, from whom? If not, why? 2) In your opinion, what could be done to prevent adolescents from experiencing violence in a romantic relationship? 3) Do you know of any activities or programs for adolescents that address DV or help adolescents? If so, what do you think of these activities or programs? 4) What do you think is the most important thing that adults need to understand about: the experiences of adolescents in relation to DV, the best ways to help them, and the best ways to pre- 
vent adolescents from experiencing DV?

\subsection{Data Analysis}

The collected data were first recorded and then transcribed verbatim in their original language (Spanish). N'Vivo 10 software (QSR, International, 2012) was used to categorize and classify the content into successive groups of statements based on their semantic proximity. The discussion content was analyzed using the thematic content analysis method. The researchers identified themes by analyzing dialogue from each focus group; the group, rather than the individual, was the unit of analysis. Themes did not emerge from a pre-existing, conceptual framework, but rather from group dialogue (Denzin \& Lincoln, 2005). Agreement between judges on the coding was used to maximize the objectivity of the data analysis process. This is a commonly suggested strategy to improve the reliability of a study by reducing the risks related to investigator bias (Patton, 2002). The names of the participants and all their personal information were changed to ensure confidentiality.

\section{Results}

Two main outcomes are presented in this section: 1) Why ask for help or not, and if so, from whom?, and 2) strategies to prevent DV. The results are supported by excerpts from the focus group, since in qualitative research citations are essential to ensure the credibility of the results presented (Creswell \& Creswell, 2018).

\subsection{Why Ask for Help or Not, and If So, from Whom?}

Most of the focus group participants identified informal sources to ask for help, such as friends and parents. However, divergences in their points of view can be seen. For some participants, friends may not be a relevant source of help: being the same age and having the same amount of experience, their advice is thought to be less appropriate, as illustrated by Maria Carolina: "Since my friends are the same age, they might have the same problem and not know how to resolve it". In addition, the participants mentioned not asking for help to maintain their autonomy in solving their problems, to avoid worrying their relatives, and to avoid having their parents take control or react in an inappropriate way, as Bruno said: "You don't want parents to know the problems you have because the parents end up trying to solve them for you."

Participants rarely mentioned teachers, social service workers, health professionals, or the police as a potential source of help. They also shared a lack of trust in teachers and difficulty in seeing them as actors playing a helping role, as Janice stated: "It's difficult to find a teacher that you can trust or who offers help". However, when adolescents have confidence in their teachers and when the situation is serious, adolescents are more likely to relate intimate experiences, such as DV situations, as Dafne affirmed: "I believe it depends on the 
teacher, because if it is a teacher that cares, (...) I think we would tell him or her".

The severity of the violence is a factor that influences the request for help, as stated by Bruno "If there is a lot [of violence], I would end up talking to my parents [even if] I don't know, they could tell me what to do". In addition, the act of reporting or asking for assistance from the police was mentioned exclusively by the girls, in particular in the case of physical violence resulting in injury, as Maria Tiare said: "If I lived through a serious act of violence [for example], bruises, injuries [as well as] telling my mum, I would denounce it."

Participants in this study recognized that they are a source of support for their peers who are experiencing DV. Talking to a friend helped them feel better when they were sad or upset about DV, and offering advice was considered the most common form of help by adolescents. According to the participants, the advice depends on whether the friend is a victim of DV or a perpetrator. In the first case, the participants suggested to the victim friend that he or she demand respect, that he or she not allow DV, or that he or she end the romantic relationship. Friends, therefore, have a preventive role, they can alert the victim of DV, as Orlando stated: When [your partner] controls you and the friends [know], they will tell you: "Hey, he's controlling you, tell him to stop."

In the second case, when it is the friend who exercises DV, helping will depend on whether or not the perpetrator is repentant. The advice given involves better communication in the couple in order to resolve conflicts and "take care" of the relationship, as illustrated by Agustín "[If my friend acts violently] I would tell him: 'You're not ok.' But if he repents, evidently, I am going to help him, [I'd say], I don't know, 'Fix it [the romantic relationship], you have to talk [with your partner]."'

Regarding the participants' expectations concerning helpers, the former agree that trusting the person who gives them help is a fundamental aspect in requesting help. Helpers' characteristics are mentioned, such as: the ability to listen with attention and empathy and the absence of prejudice. Participants in the study report that this confidence develops continuously and does not suddenly appear in adolescence, as Dafne said:

"I believe that, more than anything I would like to be heard (...), to be understood. And maybe they [parents or teachers] wouldn't say anything, but would pay attention and would listen perfectly to what I say or what I am going through. (...) paying attention to me [to] what I feel, (...) and they would say: 'Oh, she really is having a bad time.'”

In summary, the participants identified informal sources than formal sources from whom to seek help, that is, friends and parents than teachers and health professionals, respectively. The severity of DV and ensuing injuries are the main raisons for asking for help. In addition, participants agree that the trust in the person who is helping them is essential when seeking help. Finally, participants 
recognized that they are a source of support for their peers who are experiencing DV.

\subsection{Strategies for Preventing DV}

We asked participants about their knowledge of DV prevention strategies and their suggestions for improving them. Some participants stated they were not aware of any preventive action for DV, as Pedro said: “I've asked and there is not a lot of information or activities on this subject [of violence with] students". Other participants who were aware of this type of communication campaign had divergent opinions. Some participants felt these campaigns were effective, others thought they were directed at victims or perpetrators of domestic violence, the participants saying that these campaigns were more targeted at the adult population and they did not feel that this type of strategy was directed at them, as Emiliano said: "The ministry for women, or something like that, has like a rehabilitation for women who are beaten, [but] for young people I don't know [of anything]". In addition, the content of the campaigns is seen as negative, as not offering a conflict resolution option and not promoting healthy romantic relationships, as Janis stated: "It's always like 'No to mistreatment, no to this', like it doesn't happen, but it's not like 'If this is happening to you, I'll help you to stop it."'

Some participants believe that DV cannot be prevented, as Jaime said: "It [violence] can't be prevented at this age [adolescence]". According to participants, some beliefs or attitudes can interfere with seeking help, for example: thinking that DV affects all couples at one time or another, which they do not need to be informed or advised, that they need to learn from their mistakes, or simply that $\mathrm{DV}$ is not about them. The choice of ending the relationship before the DV gets worse, the shame engendered, and the idea of the romantic relationship as something private are also mentioned, as Nelson stated: "Relationships belong to couples, it's not for friends [to get involved]".

Participants mentioned the influence of friends as a possible barrier to participating in prevention activities, as Rodrigo said:

"I believe that [adolescents] are interested [in participating], but many times they don't want to..., maybe due to shyness or shame..., or because their friends aren't doing it."

Another aspect mentioned by participants that could obstruct the prevention of DV, and also hinder the development of healthy romantic relationships, is the belief of living in a society where it is more difficult to trust others. Some said this is a difference from previous generations, as Fernanda stated:

“(...) now, it's as if no one trusts anybody. So now we check [cell phones] and see everything he [the partner] has done. I think we're more affected than older generations...I think the way it's going, we could call our generation...the distrustful generation." 
Other participants thought that DV is preventable, and suggested various ideas to consider when developing DV prevention strategies. According to them, by knowing, respecting, and valuing oneself, the person can prevent DV. Trust and communication within the couple is also mentioned as a way to avoid DV and resolve conflicts immediately when they arise. The following dialogue between girls provides an example:

- What can we do to prevent violence in adolescent couples? (researcher)

- Know yourself well before trying to get to know another person... be yourself with any person. (Antonieta)

- Set limits [for the partner] (Jasmin).

The participants felt that prevention of DV should begin during childhood and transmit values such as respect, communication, tolerance, and learning conflict management strategies, thereby helping adolescents identify and prevent violence. According to the participants, beginning preventive actions in adolescence is too late, since at this stage, the first romantic experiences have already taken place, as Pedro stated:

"The reason for starting to educate [children] early is to prepare them for what they [will] face so they know how to face it, so that (...) they will know how to react and be able to avoid it".

The participants recognized a critical role for parents. However, they said that the issue of DV between parents and adolescents is rarely discussed compared to sexuality. In this regard, participants suggested setting up activities for parents to begin the conversation with their children, as Jaime said, "[Parents] should also talk [with their children] about the issue of violence [just as they] do about the issue of sexuality." Also, even if the participants agreed that school represents a fundamental space for the prevention of DV, they confirmed that DV is not a commonly discussed subject in schools, compared to the prevention of pregnancy, sexually transmitted diseases, and drug and alcohol use.

They agreed in suggesting that the training offered in schools should be based on group activities such as mixed workshops that promote discussion and sharing of opinions. Regarding who is best suited to prevent DV, participants agreed that "professional experts" are more credible than teachers, as Pedro said:

"A specialized person should come [with] videos, presentations, different types of materials to get the students and the teachers to understand how to teach it and how to carry it out."

Participants suggested avoiding large public conferences and using victims' or perpetrators' testimonies to learn about the experiences and consequences of DV. However, divergences arose about which content to use. Some participants agreed that adolescents should be educated more about subtle acts of DV, such as manipulation or control. Other participants were inclined to emphasize the physical or psychological consequences of DV. Nathan illustrated this accor- 
dingly: "Because you are trying to minimize [the violence], by showing [explicit] images, you say it is just as powerful".

Another proposed strategy involved a broader aspect of prevention by taking advantage of public space (e.g., conducting theatre activities) and of social media to make adolescents aware of the problem. However, for some adolescents, such large actions will not reach young people, while others believed that these actions are more effective in dealing with issues that concern them, as stated by Laura: "When social media...deal with a topic [like violence], they are really interesting and attract people more."

The importance of social change in gender relations as a key content in DV prevention strategy was noted. Gender inequality is an issue that has taken a greater place in the explanations of DV. Indeed, gender differences are now given as causes of aggression. For example, male violence is said to be associated with "macho societies" reproducing the idea of male superiority. The violence of girls against boys is explained by changes in gender relations favoring the assertion and the right of women in Chilean society to express themselves, as Flavia said:

"So now, I mean there was a time-I don't know if it still happens-that women let themselves be roughed up because the society was so patriarchal, that women were raised to accept being abused by men. And now, women demand more respect. And that also leads to a lot of violence. And now on the women's side, they often demand respect from the men. And it's coming with this wave of feminism. And women are feeling, I don't know, powerful, and they're demanding respect."

This discourse of gender differences was reinforced by family messages which reproduced the idea of boys as aggressors and girls as victims, as Leonor stated: "[My mom] has told me: 'You don't let anybody raise their hand [on you], first time, goodbye', [but] to my brother she says: 'Son, you must never raise your hand against a woman'."

In summary, the participants acknowledge the lack of programs or campaigns for the prevention of DV targeting and adapting to them. Regarding the barriers to seeking help and to preventing DV, participants mentioned some beliefs or attitudes about couple and about DV and the influence of friends. The feeling of living in a society where it is more difficult to trust others was mentioned as a barrier to developing healthy romantic relationships. The promotion of this type of relationship was highlighted by the participants. Prevention of DV should begin earlier and involve more the parents and social environment of the adolescents. In addition, gender is considered as a central prevention issue in a changing Chilean cultural context. The school is considered a privileged place to develop prevention strategies as well as the use of social media.

\section{Discussion}

This study, which focused on adolescents and their environment, explored factors associated with seeking help and accepting it, as well as concrete suggestions 
for DV prevention strategies in multiple settings. The results show that the actions to be undertaken must therefore target several levels of intervention and favor multi-component programs; these suggestions by the participants of the current study are consistent with the recommendations resulting from other consulted studies (Black \& Preble, 2016; Fox et al., 2014; Rothman et al., 2015; Rothman et al., 2019). In summary, the participants identified friends and parents as more common sources from whom to seek help than teachers and health professionals. The severity of DV and ensuing injuries are the main raisons for asking for help. Prevention of DV should begin earlier and involve more the parents and social environment of the adolescents. In addition, gender is considered as a central prevention issue in a changing Chilean cultural context. These propositions are particularly useful if we consider, as we will see later, the rare advances in DV prevention in Chilean public policy and DV sanctions. Using an ecological approach, the analysis of the participants' opinions allowed us to classify the suggestions into different levels. These were based on three questions proposed by Fox et al. (2014) to develop prevention strategies, namely: Who (target population), What (content), and How (methodological aspects). We then developed the following scheme that allowed us to organize the main suggestions collected from the participants' proposals (see Figure 1).

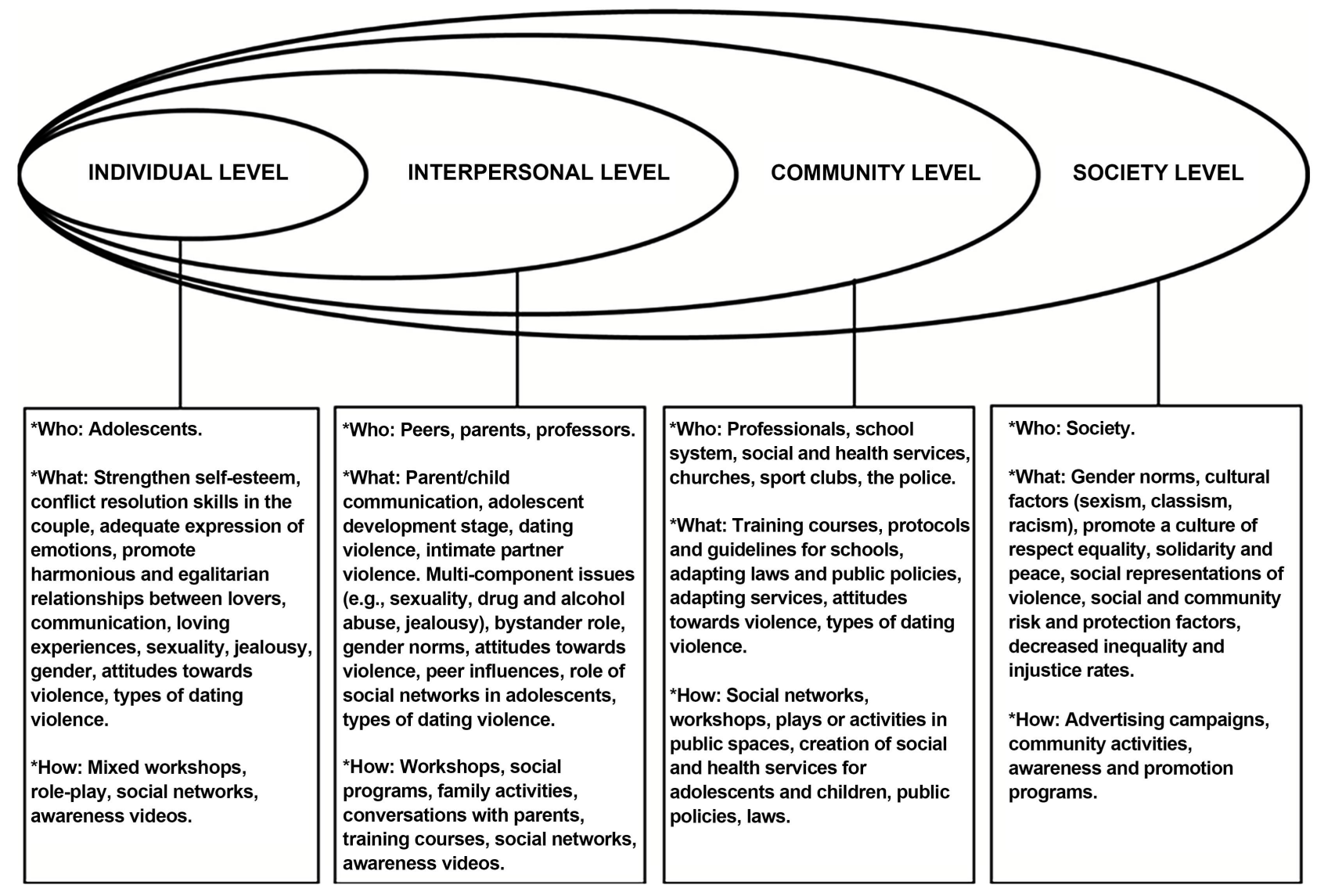

Figure 1. DV prevention according to ecological model. 


\subsection{Individual Level}

Considering that adolescent romantic relationships constitute an important learning environment for several aspects characterizing satisfying adult relationships (Valdivia-Peralta et al., 2019), the importance of promoting harmonious and egalitarian relationships among adolescents is seen as a fundamental component of prevention strategies. Participants proposed starting early and developing strategies for children. They suggested different content, for example, strengthening self-esteem, developing skills for managing relationship conflict, adequate expression of emotions, etc. This is consistent with their desire to build healthy romantic relationships, but also with their need, based on the lack of romantic relationship experience, to resolve conflicts. Different studies point to gender being associated with emotions and seeking help in DV (Fry et al., 2013; Van Camp et al., 2014). We consequently propose to take gender into consideration by developing DV prevention strategies. These would create "gender-specific" content, for example, expression of emotions and conflict resolution for boys, and for girls, talking about empowerment.

As with other studies, the participants recommended addressing all manifestations of violence, especially those that are most difficult to identify by romantic partners and that may make it difficult to seek help (e.g., jealousy, control, manipulation, sexual pressure) (Fox et al., 2014). Multi-component programs may be more accepted by adolescents. The participants mentioned, for example, different subjects of interest to adolescents (e.g., sexuality) or problems strongly associated with DV (e.g., alcohol consumption, peer tolerance of DV).

\subsection{Interpersonal Level}

Friends and peers are central actors that should be included in prevention programs (Fry et al., 2013). Participants consider that friends are an important source of help in a DV context and recognize that the peer group has a sizable influence on adolescents at this stage of life. Peer attitudes favorable to DV (Connolly \& Friedlander, 2009), or advice from friends that reinforce stereotypes or jealous behavior associated with DV or romantic ideas (Sebastián, Verdugo, \& Ortiz, 2014) are significant risk factors in DV. This is why it is important that prevention strategies reinforce the "bystander" role of friends (Banyard, 2011). However, most of the "bystander programs" have been developed in university settings (Storer, Casey, \& Herrenkohl, 2016) and focus on reactive rather than preventive behavior (Rothman et al., 2019).

DV prevention program should target people close to the adolescents, including parents and family. Despite differences of opinion among participants about these sources of help, the importance of having a close, trustworthy circle of people who are accessible to them will help to prevent some DV situations from escalating. Regarding parents, the results of this research coincide with the results of other studies on barriers to seeking help: lack of trust in parents or fear of negative reactions or judgments on their part were mentioned, as well as pre- 
venting parents from interfering in their love lives (Ocampo et al., 2007). However, coinciding with the results of a study carried out by Kast, Eisenberg, \& Sieving (2016), parents would be the ones to whom adolescents would first turn if they experienced DV or suffered serious physical injuries.

Content adapted to the parents' role as helpers would thus be required. This would include, for example, informing them about the adolescence stage, the importance of adolescent romantic relationships, and the skills required to become a source of help for their children, as revealed by the study carried out by Black \& Preble (2016) and the opinions of the participants in this study, a good helper is someone who listens attentively, without judging, and who gives emotional support; this might be the opposite of what parents often think, believing that advice on what to do would be the main way to help in these situations.

\subsection{Community Level}

At this level, four suggestions emerge from the analysis of the participants' opinions. First, it is necessary to sensitize and involve teachers and other professional actors in social, health, and police services so that they can fulfill a preventive role. Contrary to other studies that attribute genuine importance to the preventive role of teachers (Gonzalez-Guarda et al., 2014), the participants in this study did not spontaneously recognize the teachers as a source of help. They did indicate however that if the teachers had certain characteristics (e.g., inspire confidence), they might go to them. Furthermore, several studies show that if professional stakeholders or practitioners do not feel involved, adolescents' access to health and social services will be hampered (Moore et al., 2015; Khubchandani et al., 2012).

Second, according to the participants, the school is a commonly adopted place for preventing DV. However, this is a topic that is rarely discussed in school. Different studies indicate that it is essential that schools adjust the programs, curricula, protocols, and services that are provided to adolescents (Moore et al., 2015). Prevention in schools is not enough; an intersectoral approach is recommended, developed through a synergetic collaboration between the different actors involved with adolescents in such areas as sports and religion.

A third suggestion is to integrate the issue of DVs into Chile's social and health laws and policies. Its invisibility constitutes an important structural risk factor that encourages the lack of relevant social responses and reinforces the notion that DV is not a serious problem. In this regard, Chile has made some progress since 2015 when the government created a "comprehensive program to prevent violence against women", which consists of training community monitors. The program also includes awareness-raising actions, management of the training of prevention agents (professionals who work with adolescents), and intersectoral coordination actions. However, an evaluation carried out indicates that this program has no indicators signifying whether the strategy is achieving the expected changes (Macuer, Weinstein, \& Belmar, 2017). In addition, in 2020, 
the Chilean law on femicides (21.212, art 390, promulgated on March 2, 2020 (Ministerio de Justicia, 2020)) was modified and now includes crimes committed by an intimate partner even without cohabitation. Despite these advances, we still do not have prevention or punishment to effectively combat this problem.

Finally, the promotion of healthy romantic relationships and the prevention of DV through the use of social media, advertising campaigns, and activities in public spaces, would, according to the participants, better reach this group and have a positive impact on their awareness of DV.

\subsection{Societal Level}

Several authors have emphasized the importance of taking into account the cultural and socio-environmental factors influencing the behavior of adolescents and their DV experiences, which is an often-neglected component in prevention programs (Johnson et al., 2015; D’Iverno et al., 2018).

The cultural changes characterizing Chile, particularly in gender relations, must be taken into account in the development of a relevant strategy for the prevention of adolescent-related DV. Several authors have pointed out that promoting actions for a culture of gender equality is critical (Gressard, Swahn, \& Tharp, 2015; White, 2009).

Promoting a culture of respect, equality, solidarity, and peace could contribute to the prevention of DV and have a positive effect on a "distrustful" generation, thereby responding to the perception expressed by some of the participants that they are living in a threatening society that generates mistrust. Strengthening the social fabric of Chile is essential for the prevention of DV and promoting trusting relationships among adolescents and between them and those close to them.

\section{Conclusion}

Prevention strategies in southern countries remain poorly documented. This research consequently helps fill two main gaps. In the first place, our study elaborates a proposal based on adolescents' experiences and viewpoints as to the best ways to prevent. Secondly, the specific strategies given are based on an ecological systems theory that allows a better understanding of the complexity of the problem and the interaction between the different levels (i.e., individual, interpersonal, community, and social levels), and the responses adapted to the context. Our proposal, therefore, develops factors that are not commonly considered in the literature, such as social and environmental factors.

Knowledge about the romantic trajectories of adolescents and their DV experiences is limited in Chile. Knowing them better would allow us to discover the protective aspects that exist, enhance them, and understand the mechanisms that operate in a DV emergency. Future studies are therefore needed to examine the links between adolescents' experiences, their environment, and the sociocultural context so as to better guide prevention strategies. This research allows us to state that a strategic approach centered on adolescents is necessary and that tak- 
ing into account their experiences and the context in which they live is crucial.

However, some limitations of the present study deserve to be highlighted. First, regarding the sampling strategy, adolescents from ethnic or sexual minorities, or from rural areas, were not explicitly selected. Second, the recruitment method prioritized students, neglecting the more marginalized adolescent population, which may have more risk factors, as noted by Crooks et al. (2019). Third, due to the collective nature of focus groups, it is possible that social desirability influenced the participants' opinions. Likewise, because adolescents do not always spontaneously talk in groups about personal experiences, it was not easy for the participants to relate their experiences and representations of DV.

Despite these limitations, the present study proposes original findings that contribute to the development of DV prevention strategies, taking into account the diversity of gender and socioeconomic status among participants. It proposes interesting clues not only for the Chilean context, but also for other Latin American countries, and can enrich the proposals that have emerged from the northern hemisphere. It especially highlights the importance of DV prevention and intervention programs for adolescents with a multi-component approach (Mazza et al., 2021) and collaborative and creative support (Ragavan et al., 2020). It likewise underlines the importance of taking sociocultural factors into account in DV programs.

\section{Acknowledgements}

The authors further wish to thank the adolescents who took part in the study for their cooperation. The authors received financial support for the research, authorship, and publication of this article from CONICYT, Chile (National Commission for Scientific and Technological Research) and from University of Concepción, Chile.

\section{Conflicts of Interest}

The authors declare no conflicts of interest regarding the publication of this paper.

\section{References}

Adams, H. L., \& Williams, L. R. (2011b). What They Wish They Would Have Known: Support for Comprehensive Sexual Education from Mexican American and White Adolescents' Dating and Sexual Desires. Children and Youth Services Review, 33, 1875-1885. https://doi.org/10.1016/j.childyouth.2011.05.013

Adams, H., \& Williams, L. (2011a). Advice from Teens to Teens about Dating: Implications for Healthy Relationships. Children and Youth Services Review, 33, 254-264. https://doi.org/10.1016/j.childyouth.2010.09.008

Banyard, V. (2011). Who Will Help Prevent Sexual Violence: Creating an Ecological Model of Bystander Intervention. Psychology of Violence, 1, 216-229.

https://doi.org/10.1037/a0023739

Black, B. M., Tolman, R., Callahan, M., Saunders, M., \& Weisz, A. N. (2008). When Will 
Adolescents Tell Someone about Dating Violence Victimization? Violence against Women, 14, 741-758. https://doi.org/10.1177/1077801208320248

Black, B., \& Preble, K. (2016). Parental Responses to Youths' Reports of Teen Dating Violence: Recommendations from Parents and Youth. Journal of Adolescence, 51, 144-155. https://doi.org/10.1016/j.adolescence.2016.06.008

Bronfenbrenner, U. (1979). The Ecology of Human Development: Experiments by Nature and Design. Harvard University Press.

Burton, C., Halpern-Felsher, B., Rehm, R., Rankin, S., \& Humphreys, J. (2013). "It Was Pretty Scary": The Theme of Fear in Young Adult Women's Descriptions of a History of Adolescent Dating Abuse. Issues in Mental Health Nursing, 34, 803-813. https://doi.org/10.3109/01612840.2013.827286

Connolly, J., \& Friedlander, L. (2009). Peer Group Influences on Adolescent Dating Aggression. The Prevention Researcher, 16, 8-11. https://doi.org/10.1037/e515092009-002

Creswell, J. W., \& Creswell, J. D. (2018). Research Design: Qualitative, Quantitative, and Mixed Methods Approaches. Sage.

Crooks, C., Jaffe, P., Dunlop, C., Kerry, A., \& Exner-Cortens, D. (2019). Preventing Gender-Based Violence among Adolescents and Young Adults: Lessons from 25 Years of Program Development and Evaluation. Violence against Women, 25, 29-55. https://doi.org/10.1177/1077801218815778

Cui, M., Ueno, K., Gordon, M., \& Fincham, F. (2013). The Continuation of Intimate Partner Violence from Adolescence to Young Adulthood. Journal of Marriage and Family, 75, 300-313. https://doi.org/10.1111/jomf.12016

D'Iverno, A. S., Kearns, M. C., \& Reidy, D. E. (2018). Introduction to the Special Issue: The Role of Public Policies in Preventing IPV, TDV, and SV. Journal of Interpersonal Violence, 33, 3259-3266. https://doi.org/10.1177/0886260518798360

Denzin, N. K., \& Lincoln, Y. S. (2005). The Handbook of Qualitative Research. Sage Publications Ltd.

Dutton, D. G. (1985). An Ecological Nested Theory of Male Violence towards Intimates. International Journal of Women's Studies, 8, 404-413.

Fellmeth, G. L. T., Heffernan, C., Nurse, Habibula, S., \& Sethi, D. (2013). Educational and Skills-Based Interventions for Preventing Relationship and Dating Violence in Adolescents and Young Adults: A Systematic Review. Cochrane Database of Systematic Reviews, No. 6, CD004534. https://doi.org/10.1002/14651858.CD004534.pub3

Fernández-Fuertes, A. A., \& Fuertes, A. (2010). Physical and Psychological Aggression in Dating Relationships of Spanish Adolescents: Motives and Consequences. Child Abuse \& Neglect, 34, 183-191. https://doi.org/10.1016/j.chiabu.2010.01.002

Foshee, V. A., Benefield, T. S., Ennett, S. T., Bauman, K. E., \& Suchindran, C. (2004). Longitudinal Predictors of Serious Physical and Sexual Dating Violence Victimization during Adolescence. Preventive Medicine, 39, 1007-1016. https://doi.org/10.1016/j.ypmed.2004.04.014

Fox, C., Hale, R., \& Gadd, D. (2014). Domestic Violence Abuse Prevention Education: Listening to the Views of Young People. Sex Education, 14, 28-41. https://doi.org/10.1080/14681811.2013.816949

Fredland, N., Ricardo, I., Campbell, J., Sharps, P., Kub, J., \& Yonas, M. (2005). The Meaning of Dating Violence in the Lives of Middle School Adolescents: A Report of a Focus Groups Study. Journal of School Violence, 4, 95-114. https://doi.org/10.1300/J202v04n02_06

Fry, D., Messinger, A., Rickert, V., O’Connor, M., Palmetto, N., Lessel, H., \& Davidson, L. 
(2013). Adolescent Relationship Violence: Help-Seeking and Help-Giving Behaviors among Peers. Journal of Urban Health: Bulletin oh the New York Academy of Medicine, 91, 320-334. https://doi.org/10.1007/s11524-013-9826-7

Gallopin, C., \& Leigh, L. (2009). Teen Perceptions of Dating Violence, Help-Seeking, and Roles of Schools. The Prevention Researcher, 16, 17-20.

Gonzalez-Guarda, R. M., Cummings, A. M., Pino, K., Malhotra, K., Becerra, M. M., \& Lopez, J. E. (2014). Perceptions of Adolescents, Parents and School Personnel from a Predominantly Cuban American Community Regarding Dating and Teen Dating Violence Prevention. Research in Nursing \& Health, 37, 117-127.

https://doi.org/10.1002/nur.21588

Gracia Leiva, M., Puente Martínez, A., Ubillos Landa, S., \& Páez Rovira, D. (2019). La violencia en el noviazgo (VN): Una revisión de meta-análisis. Anales de psicología, 35, 300-313. https://doi.org/10.6018/analesps.35.2.333101

Gressard, L. A., Swahn, M. H., \& Tharp, A. (2015). A First Look at Gender Inequality as a Societal Risk Factor for Dating Violence. American Journal of Preventive Medicine, 49, 448-457. https://doi.org/10.1016/j.amepre.2015.05.017

Heise, L. (1998). Violence against Women. An Integrated, Ecological Framework. Violence against Women, 4, 262-290. https://doi.org/10.1177/1077801298004003002

Johnson, R. M., Parker, E. M., Rinehart, J., Nail, J., \& Rothman, E. F. (2015). Neighborhood Factors and Dating Violence among Youth. A Systematic Review. American Journal of Preventive Medicine, 49, 458-466. https://doi.org/10.1016/j.amepre.2015.05.020

Kast, N., Eisenberg, M., \& Sieving, R. (2016). The Role of Parent Communication and Connectedness in Dating Violence Victimization among Latino Adolescents. Journal Interpersonal Violence, 31, 1932-1955. https://doi.org/10.1177/0886260515570750

Khubchandani, J., Price, J., Thompson, A., Dake, J., Wiblishauser, M., \& Telijohann, S. (2012). Adolescent Dating Violence. A National Assessment of School Counselors' Perceptions and Practices. Pediatrics, 130, 1-9. https://doi.org/10.1542/peds.2011-3130

Letendre, J., \& Williams L. (2014). "I Hear You”: Using Focus Groups to Give Voice to Adolescent Girls' Experiences with Violence. Social work with Groups, 37, 114-128. https://doi.org/10.1080/01609513.2013.823832

Macuer, T., Weinstein, M., \& Belmar, C. (2017). Informe final de evaluación. Programa de prevención integral de la violencia contra las mujeres y programa de atención, protección y reparación integral de violencias contra las mujeres [Final Evaluation Report. Comprehensive Prevention of Violence against Women Program and Comprehensive Care, Protection and Reparation Program for Violence against Women]. Ministerio de la Mujer y equidad de género. Servicio Nacional de la Mujer y equidad de género [Ministry of Women and Gender Equality. National Women's Service and Gender Equality].

Mayoyo, N., Ogeno, J., \& Likoye, F. (2020). The Impact of Contemporary Communication Technology on Undergraduate Students' Dating Violence Episodes: An Exploration of Routine Activity Theory. Open Journal of Social Sciences, 8, 161-175. https://doi.org/10.4236/jss.2020.89011

Mazza, M., Marano, G., del Castillo, A. G., Chieffo, D., Monti, L., Janiri, D., Sani, G. et al. (2021). Intimate Partner Violence: A Loop of Abuse, Depression and Victimization. World Journal of Psychiatry, 11, Article No. 215. https://doi.org/10.5498/wjp.v11.i6.215

Ministerio de Justicia [Ministry of Justice] (2005, October). Ley 20.066. Published in the Official Gazette. https://www.leychile.cl

Ministerio de Justicia [Ministry of Justice] (2020, March). Ley 21.212. Published in the 
Official Gazette. https://www.leychile.cl

Ministerio de Justicia [Ministry of Justice] (2021). Ley 21.393. Published in the Official Gazette on November 2021. https://www.leychile.cl

Ministerio de Salud [MINSAL] [Ministry of Health] (2013). Programa nacional de salud integral de adolescentes y jóvenes. Plan de acción 2012-2020. Santiago de Chile.

Moore, A., Sargenton, K., Ferranti D., \& Gonzalez-Guarda, R. (2015). Adolescent Dating Violence: Supports and Barriers in Accessing Services. Journal of Community Health Nursing, 31, 39-52. https://doi.org/10.1080/07370016.2015.991668

Morgan, D. L. (1997). Focus Groups as Qualitative Research (2nd ed.). Qualitative Research Methods Series, Vol. 16, Sage University. https://doi.org/10.4135/9781412984287

Ocampo, B., Shelley, G., \& Jaycox, L. (2007). Latino Teens Talk about Help Seeking and Help Giving in Relation to Dating Violence. Violence against Women, 13, 172-189. https://doi.org/10.1177/1077801206296982

Patton, M. Q. (2002). Qualitative Research \& Evaluation Methods (3rd ed.). Sage.

Pittenger, S., Huit, T., \& Hansen, D. (2016). Applying Ecological Systems Theory to Sexual Revictimization of Youth: Review with Implications for Research and Practice. Aggression and Violent Behavior, 26, 35-45. https://doi.org/10.1016/j.avb.2015.11.005

Ragavan, M. I., Culyba, A. J., Muhammad, F. L., \& Miller, E. (2020). Supporting Adolescents and Young Adults Exposed to or Experiencing Violence during the COVID-19 Pandemic. The Journal of Adolescent Health, 67, 18.

https://doi.org/10.1016/j.jadohealth.2020.04.011

Rothman, E. F., Edwards, K. M., Rizzo, A. J., Kearns, M., \& Banyard, V. L. (2019). Perceptions of Community Norms and Youth's Reactive and Proactive Dating and Sexual Violence Bystander Action. American Journal of Community Psychology, 63, 122-134. https://doi.org/10.1002/ajcp.12312

Rothman, E., Bair-Merritt, M., \& Tharp, A. (2015). Beyond the Individual Level. Novel Approaches and Considerations for Multilevel Adolescent Dating Violence Prevention. American Journal of Preventive Medicine, 49, 445-447. https://doi.org/10.1016/j.amepre.2015.05.019

Rothman, E., Miller, E., Terpeluk, A., Glauber, A., \& Randel, J. (2011). The Proportion of U.S. Parents Who Talk with Their Adolescent Children about Dating Abuse. Journal of Adolescent Health, 49, 216-218. https://doi.org/10.1016/j.jadohealth.2011.05.005

Rueda, H., Williams, L., \& Nagoshi, J. (2015). Help-Seeking and Help-Offering for Teen Dating Violence among Acculturating Mexican American Adolescents. Children and Youth Services Review, 53, 219-228. https://doi.org/10.1016/j.childyouth.2015.04.001

Sabina, Ch., Cuevas, C., \& Rodriguez, R. (2014). Who to Turn to? Help-Seeking in Response to Teen Dating Violence among Latinos. Psychology of Violence, 4, 348-362. https://doi.org/10.1037/a0035037

Sebastián, J., Verdugo, A., \& Ortiz, B. (2014). Jealousy and Violence in Dating Relationships: Gender-Related Differences among a Spanish Sample. Spanish Journal of Psychology, 17, E94. https://doi.org/10.1017/sjp.2014.99

Servicio Nacional de la Mujer (SERNAM) (2012). Plan Nacional de Violencia Intrafamiliar en Chile (Noviembre 2012-Diciembre 2013). Santiago. http://www.sernam,gob.cl

Storer, H. L., Casey, E., \& Herrenkohl, T. (2016). Efficacy of Bystander Programs to Prevent Dating Abuse among Youth and Young Adults: A Review of the Literature. Trauma, Violence \& Abuse, 17, 256-269. https://doi.org/10.1177/1524838015584361

Sundaram, V. (2016). "You Can Try, But You Won't Stop It. It'll Always Be There": 
Youth Perspectives on Violence and Prevention Schools. Journal of Interpersonal Violence, 31, 652-676. https://doi.org/10.1177/0886260514556106

Torche, F. (2005). Unequal but Fluid: Social Mobility in Chile in Comparative Perspective. American Sociological Review, 70, 422-450. https://doi.org/10.1177/000312240507000304

Underwood, M. K., \& Rosen, L. H. (2009). Gender, Peer Relations, and Challenges for Girlfriends and Boyfriends Coming Together in Adolescence. Psychology of Women Quarterly, 33, 16-20. https://doi.org/10.1111/j.1471-6402.2008.01468.x

Valdivia-Peralta, M., Fonseca-Pedrero, E., González-Bravo, L. A., \& Paino, M. (2019). Invisibilización de la violencia en el noviazgo en Chile: Evidencia desde la investigación empírica. Perfiles Latinoamericanos, 27, 1-31.

https://doi.org/10.18504/pl2754-012-2019

Van Camp, T., Hébert, M., Guidi, E., Lavoie, F., \& Blais, M. (2014). Teens' Self-Efficacy to Deal with Dating Violence as Victim, Perpetrator or Bystander. International Review of Victimology, 20, 289-303. https://doi.org/10.1177/0269758014521741

Weisz, A., \& Black, B. (2009) Help-Seeking and Help-Giving for Teen Dating Violence. The Prevention Researcher, 16, 12-16. https://doi.org/10.1037/e515092009-003

White, J. (2009). A Gendered Approach to Adolescent Dating Violence: Conceptual and Methodological Issues. Psychology of Women Quarterly, 33, 1-15.

https://doi.org/10.1111/j.1471-6402.2008.01467.x 